\title{
Modifiye Juglans Regia L. Yaprağı Kullanarak Sulu Çözeltilerden Reaktif Red 120'nin Biyosorpsiyonu
}

\author{
Ferda Özmal $^{1 *}$, Gönül Duman ${ }^{1}$ \\ 1* Kütahya Dumlupınar Üniversitesi, Fen-Edebiyat Fakültesi, Biyokimya Bölümü, Kütahya, Türkiye, (ORCID: 0000-0002-8393-5279, 0000-0002-8513-9487), \\ ferda.ozmal@dpu.edu.tr, gonulduman0388@gmail.com
}

(İlk Geliş Tarihi 19 Mart 2021 ve Kabul Tarihi 27 Haziran 2021)

(DOI: $10.31590 /$ ejosat.898496)

ATIF/REFERENCE: Özmal, F. \& Duman G. (2021). Modifiye Juglans Regia L. Yaprağı Kullanarak Sulu Çözeltilerden Reaktif Red 120 'nin Biyosorpsiyonu. Avrupa Bilim ve Teknoloji Dergisi, (25), 256-266.

$\ddot{O} \mathbf{z}$

Bu çalışmada ham (HCY) ve sitrik asit ile modifiye edilmiş Juglans regia L. (ceviz) yaprağının (MCY) sulu çözeltiden RR120 boyarmaddesini biyosorpsiyonu araştırılmıştır. Kullanılan biyokütlelerin karakterizasyon için FT-IR spektrumları ve SEM görüntüleri alınmış, zeta potansiyel analizleri yapılmıştır. Deneyler kesikli sistemde pH, biyosorban miktarı, başlangıç boyarmadde konsantrasyonu, temas süresi ve sıcaklığın fonksiyonu olarak gerçekleştirilmiştir. Çözeltilerdeki boyarmadde konsantrasyonları UVvisible spektrofotometre ile tayin edilmiştir. Biyosorpsiyon verileri her iki biyokütle için de en iyi Langmuir izoterm modeline uyum göstermiştir. Tek tabakalı maksimum biyosorpsiyon kapasitesi $50{ }^{\circ} \mathrm{C}$ 'de $\mathrm{HCY}$ ve MCY için sırasıyla $135,16 \mathrm{mg} / \mathrm{g}$ ve $181,21 \mathrm{mg} / \mathrm{g}$ olarak tespit edilmiştir. Deneysel bulgular, yalancı-birinci dereceden ve yalanc1-ikinci dereceden kinetik modellere uygulanmış ve RR120'nin HCY ve MCY üzerine biyosorpsiyon kinetiğinin yalanc1-ikinci dereceden kinetik modelle açıklanabildiği sonucuna varılmıştır.

Anahtar Kelimeler: Biyosorpsiyon, Biyosorpsiyon kinetiği, Ceviz yaprağı, Freundlich izotermi, Langmuir izotermi, RR120.

\section{Biosorption of Reactive Red 120 from Aqueous Solutions by Using Modified Juglans Regia L. Leaf}

\begin{abstract}
In this study, biosorption of RR120 dye from aqueous solution by Juglans regia L. (walnut) leaf in natural (HCY) and citric acid modified (MCY) form was investigated. The biomasses were characterized by means of FT-IR spectra, SEM images and zeta potential analyses. The experiments were carried out in the batch system as a function of $\mathrm{pH}$, biosorbent amount, inital dye concentration, contact time and temperature. The dye concentrations in the solutions were determined by UV-visible spectrophotometer. Biosorption data fits best with the Langmuir isotherm model for both biomasses. Monolayer maximum biosorption capacity at $50{ }^{\circ} \mathrm{C}$ was determined as $135,16 \mathrm{mg} / \mathrm{g}$ and $181,21 \mathrm{mg} / \mathrm{g}$ for $\mathrm{HCY}$ and MCY, respectively. Experimental findings were applied to pseudo-first order and pseudo-second order kinetic models and it was concluded that the biosorption kinetics of RR120 on HCY and MCY could be explained by pseudo-second order kinetic model.
\end{abstract}

Keywords: Biosorption, Biosorption kinetics, Juglans regia L. leaf, Freundlich isotherm, Langmuir isotherm, RR120.

*Sorumlu Yazar: ferda.ozmal@dpu.edu.tr 


\section{Giriş}

Bilim ve teknoloji alanındaki ilerlemeler, endüstrileşme adına büyük avantajlar sağlarken hızlı nüfus artışı ile birlikte çevre kirliliği problemini de beraberinde getirmiştir. Artan çevre kirliliği canlı türlerinin sayısında ciddi oranda azalmaya sebep olmuştur (Thieman and Palladino, 2004). Endüstriyel atık suların akarsu, göller, deniz veya diğer alıcı ortamlara verilmeden önce çeşitli yöntemlerle arıtılmaları ve atık su yönetmeliklerine göre toksik maddelerin belli oranlarda giderilmesi gerekmektedir. Endüstriyel atık sularda bulunan yüksek oranlardaki organik maddelerden birisi de boyar maddelerdir (Scmit, 1981). Tekstil endüstrisinde kullanılan boyarmaddelerin \%10-15'inin atık suya geçtiği bilinmektedir. Bu miktar yaklaşık yılda 280.000 ton boya içeren atık suyun dünya genelinde alıcı ortamlara verildiği anlamına gelmektedir (Gül ve Yıldız, 2020). Reaktif azo boyarmaddeler, yapılarında heterosiklik ve aromatik gruplarla birlikte en az bir veya daha fazla sayıda azo zinciri $(-\mathrm{N}=\mathrm{N}-)$ içeren boyarmaddelerdir ve yıllık boyarmadde üretiminin $\% 50$ 60'ını oluşturmaktadırlar (Katherasan ve ark., 2018; Bulgariu ve ark., 2019). Tekstil boyama prosesinde, reaktif azo boyarmaddelerin yaklaşık \%10-60'ının atık sularla çevreye verildiği tahmin edilmektedir (Munagapati ve ark., 2019).

Son yıllarda büyük bir sorun teşkil eden atık sulardaki boyarmaddelerin, çevre dostu, bol bulunan ve ucuz olan tarımsal atıklar ile giderimi büyük dikkat çekmektedir (JahanbanEsfahlan ve ark., 2020). Biyolojik materyal kullanılarak, adsorpsiyon mekanizması ile atık su arıtımı biyosorpsiyon olarak ifade edilmektedir. Farklı türlerde tarımsal yan ürünlerin biyosorpsiyonda düşük maliyetli ve etkin giderim verimleri ile kullanılabilmesi için araştırmalar hızla devam etmektedir (Chaleshtori ve ark., 2017; Saleh ve ark., 2019). Biyosorpsiyon prosesi, biyosorbentin; yüksek verimlilikle yeniden kullanılabilmesi, yüksek seçicilik göstermesi, büyük hacimli atık sularda verimli bir şekilde uygulanabilmesi ve maliyetinin düşük olması gibi avantajlara sahiptir (Bayramoglu ve ark., 2006).Bu sebeple biyosorpsiyon atıksu arıtımında geleneksel yöntemlere önemli bir alternetif oluşturmaktadır.

$\mathrm{Bu}$ çalışmada Juglans regia L. (ceviz) yaprağından hazırlanan biyosorbanlar ile tekstil endüstrisinde kullanılan anyonik bir boyarmadde olan Reaktif Red 120'nin (RR120) biyosorpsiyonu araştırılmıştır. Hazırlanan ham ve modifiye biyosorbanların sulu çözeltiden RR120 biyosorpsiyon performansı $\mathrm{pH}$, adsorban miktarı, başlangıç konsantrasyonu, temas süresi ve sicaklık gibi parametrelerin fonksiyonu olarak karşılaştırmalı olarak incelenmiştir.

\section{Materyal ve Metot}

\subsection{Biyosorbanın Temini ve Hazırlanması}

Deneylerde biyosorban olarak kullanilan ceviz (JUGLANS $R E G \dot{I} A$ L.) yaprağı, Afyonkarahisar Merkezindeki aktarlardan temin edilmiştir. Kurutulmuş olarak temin edilen ceviz yaprakları deiyonize su ile yıkanarak, oda koşullarında kurumaya bırakılmıştır. Kuruyan yapraklar Retsch Rm 200 marka ögütücüde öğütülerek tekrar deiyonize su ile yıkanmıştır. 80 ${ }^{\circ} \mathrm{C}$ 'deki etüvde 48 saat kurutularak $250 \mu \mathrm{m}$ boyutlarındaki eleklerden geçirilmiş ve elek altı malzeme nem içeriğini uzaklaştırmak için son kez $80{ }^{\circ} \mathrm{C}$ etüvde 2 saat kurutulduktan sonra deneylerde kullanılmak üzere şişelenmiştir.

\subsection{Boyarmadde Çözeltilerinin Hazırlanması}

Deneylerde kullanılmak üzere bir tekstil fabrikasından temin edilmiş olan RR120 boyarmaddesinden herhangi bir saflaştırma işlemi yapmadan $1000 \mathrm{mg} / \mathrm{L}$ derişiminde stok çözeltiler hazırlanmış olup, stok çözeltilerden, gerekli seyreltmeler yapılarak istenilen konsantrasyonda çözeltiler elde edilmiş ve deneylerde kullanılmıştır. Çözeltilerin pH'larının istenilen değerlere ayarlanmasında $0,1 \mathrm{M} \mathrm{HCl}$ ve $0,1 \mathrm{M} \mathrm{NaOH}$ çözeltileri kullanılmış ve pH ölçümleri WTW 7110 model pH metre ile yapılmıştır.

RR120 (molar ağırlık $1469.98 \mathrm{~g} / \mathrm{mol}$, ve lineer formül $\mathrm{C}_{44} \mathrm{H}_{24} \mathrm{Cl}_{2} \mathrm{~N}_{14} \mathrm{Na}_{6} \mathrm{O}_{20} \mathrm{~S}_{6}$ ) reaktif olarak altı sülfonik asit grubu ve iki fenolik $\mathrm{OH}$ grubu içermektedir (Paul ve ark., 2011).

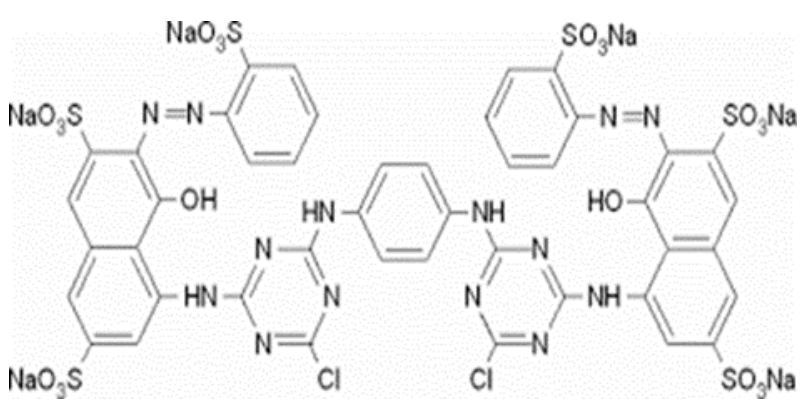

\section{Şekil 2.1 RR120 boyarmaddesinin kimyasal yapısı (Paul ve ark., 2011)}

\subsection{Biyosorbanın Modifikasyonu}

Temin edilen ceviz yaprakları yıkama, kurutma ve öğütme işlemlerinden geçirilerek $250 \mu \mathrm{m}$ eleklerden elenmiş ve elek altı malzeme HCY (ham ceviz yaprağı) olarak kodlanmış ve deneylerde kullanılmak üzere hazır hale getirilmiştir. Biyosorpsiyon kapasitesini arttırmak için HCY nin sitrik asitle modifikasyonu çalışılmıştır. Bunun için $1 \mathrm{M}$ sitrik asit çözeltisi hazırlanmış ve HCY nin gramı başına bu çözeltiden $10 \mathrm{~mL}$ alınarak 2 saat karıştırılmış ve daha sonra süzme işlemine tabi tutulmuştur. Tekrar kurutulup ögütülen biyosorban $\mathrm{pH}$ nötr oluncaya kadar yıkanmıştır. Her aşamada $80{ }^{\circ} \mathrm{C}$ ' deki etüvde 48 saat kurutularak $250 \mu \mathrm{m}$ boyutlarındaki eleklerden geçirilen biyosorbanın bu şekilde sitrik asitle modifikasyonu sağlanmıştır. Sitrik asitle modifiye edilmiş biyosorban MCY(modifiye ceviz yaprağı) olarak kodlanmıştır (dos Santos ve ark., 2019).

\subsection{Kullanılan Cihazlar}

Deneylerde kullanılan biyosorbanın ham haldeyken ve sitrik asitle modifikasyon işleminden sonra karakterize edilebilmesi için biyosorbana FT-IR, SEM ve ZETA potansiyeli analizleri uygulanmıştır. FT-IR analizi Kütahya Dumlupınar Üniversitesi İleri Teknolojiler Merkezinde (İLTEM) bulunan Bruker Alpha Platium ATR cihazıyla, SEM analizi ise yine İLTEM de yer alan FEI Nova Nanosem 650 markalı cihazla gerçekleştirilmiştir. Zeta potansiyeli ise ODTÜ Merlab da bulunan Malvern Zetasizer NanoZS90 marka cihazla yapılmıştır. Hazırlanan biyosorbanlar optimum koşullarda RR120 boyarmaddesi ile yüklendikten sonra FT-IR, SEM ve ZETA potansiyeli analizleri tekrarlanarak biyosorbanın yüklü ve yüksüz hallerindeki yapıları karşılaştırılmıştır. 
Deneylerin her aşamasında çözeltilerdeki boyarmadde miktarları Kütahya Dumlupınar Üniversitesi Fen Edebiyat Fakültesi Kimya Bölümü Bor Araştırma Laboratuvarında bulunan SHIMADZU 2550 markalı UV spektrofotometre cihazıyla ölçülmüştür.

\subsection{Kesikli Sistemle Biyosorpsiyon Deneyleri}

Biyosorpsiyon deneylerinde $\mathrm{pH}$, biyosorban miktarı, temas süresi ve sicaklık, boyarmadde konsantrasyonu gibi parametrelerin biyosorpsiyon üzerine etkileri çalışılmıştır. $\mathrm{pH}$ etkisini çalışmak için, $250 \mu \mathrm{m}$ boyutundaki $0,05 \mathrm{~g}$ biyosorbanlar üzerine $50 \mathrm{~mL} 100 \mathrm{mg} / \mathrm{L}$ RR120 boyarmaddesi ilave edilmiş ve pH değerleri 1- 9 aralığında değiştirilerek $500 \mathrm{rpm}$ de 1 saat karıştırılmıştır. Biyosorban miktarının biyosorpsiyondaki etkisini belirlemek için, 0,025-0,4 g' lik biyosorbanlar üzerine $100 \mathrm{mg} / \mathrm{L}$ başlangıç derişimindeki RR120'den 50 mL ilave edilmiş, pH'ları belirlenen optimum pH' a ayarlandiktan sonra $500 \mathrm{rpm}$ ' de 1 saat oda sıcaklığında karıştırılarak süzülmüştür. RR120 boyarmadesinin başlangıç konsantrasyonlarının biyosorpsiyon üzerine etkisini araştırmak için ise, başlangıç konsatrasyonları $50-400 \mathrm{mg} / \mathrm{L}$ aralığında çalışılmıştır. Elde edilen deneysel veriler, Langmuir ve Freundlich izoterm eşitliklerine uygulanarak biyosorpsiyon süreci $20{ }^{\circ} \mathrm{C}, 30{ }^{\circ} \mathrm{C}, 40{ }^{\circ} \mathrm{C}$ ve $50{ }^{\circ} \mathrm{C}$ olmak üzere dört ayrı sıcaklık için çalışılmış ve sıcaklığın bu süreç üzerindeki etkisi de araştırılmıştır. RR120 boyarmaddesinin biyosorbanlar tarafindan farklı sicaklık ve sürelerde biyosorpsiyonunda, biyosorpsiyon mekanizmasını aydınlatmak amaciyla elde edilen deneysel veriler yalanc1birinci dereceden ve yalanc1-ikinci dereceden kinetik modellerine uygulanmıştır. Temas süresi 5-180 dakika aralığında, sıcaklık ise $20-50{ }^{\circ} \mathrm{C}$ aralığında incelenmiştir.

Deneysel çalışmada, biyosorpsiyon sürecinde dengeye ulaşıldığı zaman çözeltiler mavi bant süzgeç kağıdından süzülmüş, çözeltide kalan boyarmadde konsantrasyonları UV spektrofotometre ile tayin edilmiştir. Deneyler 3 tekrarlı yapılmıştır. Biyosorpsyon yüzdesi:

$\%$ Biyosorpsiyon $=\frac{\mathrm{C} i-\mathrm{Cs}}{\mathrm{Ci}} x 100$

formülü ile hesaplanmıştır. $C_{i}$ ve $C_{s}$ sırasıyla boyarmaddenin başlangıç ve biyosorpsiyondan sonraki son konsantrasyonlardır.

\section{Araştırma Sonuçları ve Tartışma}

\subsection{Biyosorbanın Karakterizasyonu}

\subsubsection{FT-IR Analizleri}

HCY ve MCY biyokütlelerinin yüksüz ve boyarmadde yüklü durumdaki spektrumları alınarak karşılaştırılmıştır.

Şekil 3.1 ve 3.2 de sirasıyla kurutulmuş yüksüz ve yüklü durumdaki HCY ve MCY biyokütlelerinin 400-4000 $\mathrm{cm}^{-1}$ aralığındaki FT-IR spektrumları verilmiştir. Biyosorbentboyarmadde etkileşimleri hakkında bilgi edinebilmek için spektrumlar birbirleri ile kiyaslanarak yorumlanmaya çalışılmıştır.

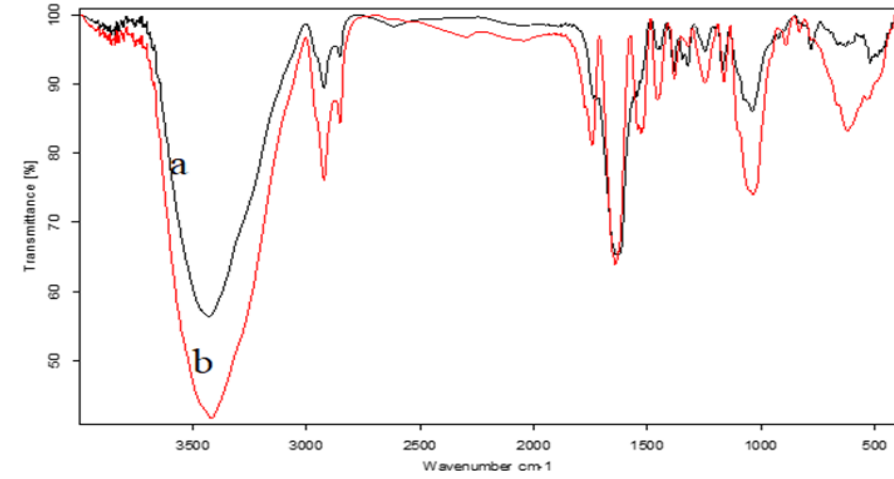

\section{Şekil 3.1. HCY biyokütlesinin FT-IR spektrumları (a)yüksüz (b)boyarmadde yüklü}

Şekil 3.1 de en belirgin olarak, 3415-3430 $\mathrm{cm}^{-1}$ aralığında $\mathrm{O}-\mathrm{H}$ ve $\mathrm{N}-\mathrm{H}$ gerilme titreşimlerine ait pikler, 2853-2960 $\mathrm{cm}^{-1}$ aralığında alifatik zincire bağlı $-\mathrm{CH}_{2}$ ve $-\mathrm{CH}_{3}$ gruplarının gerilme titreşim pikleri, $1600-1800 \mathrm{~cm}^{-1}$ aralığında $\mathrm{C}=\mathrm{O}$ gerilme titreşim pikleri, $1417-1570 \mathrm{~cm}^{-1}$ aralığında $\mathrm{C}=\mathrm{N}$ ve $\mathrm{C}=\mathrm{C}$ gerilme titreşim pikleri, $1160-1325 \mathrm{~cm}^{-1}$ aralığında $\mathrm{C}-\mathrm{O}$ gerilme titreşim pikleri ve $1247 \mathrm{~cm}^{-1}$ de ise $\mathrm{S}-\mathrm{O}$ gerilim titreşimine ait pikler gözlenmektedir.

Boyarmadde biyosorpsiyonundan sonra $\mathrm{O}-\mathrm{H}$ ve $\mathrm{N}-\mathrm{H}$ gerilim titreşimlerine ait pikler, $\mathrm{C}=\mathrm{O}, \mathrm{C}=\mathrm{N}$ ve $\mathrm{C}=\mathrm{C}$ gerilme titreşim pikleri ile $\mathrm{C}-\mathrm{O}$ gerilme titreşim piklerinde daha düşük dalga sayıs1 yönünde kaymalar gözlenmiştir. $\mathrm{Bu}$ durum HCY biyokütlesi yüzeyindeki fonksiyonel gruplar ile boyarmaddenin etkileştiği yönünde yorumlanmaktadır. Benzer sonuçlar RR120 nin Moringa Oliefera tohumları üzerine (Çelekli ve ark., 2019), kuaterner amin ile modifiye edilmiş portakal kabuğu tozu üzerine (Munagapati ve ark., 2019); ve Chara contraria üzerine (Çelekli ve ark., 2012) biyosorpsiyonunda da gözlenmiştir.

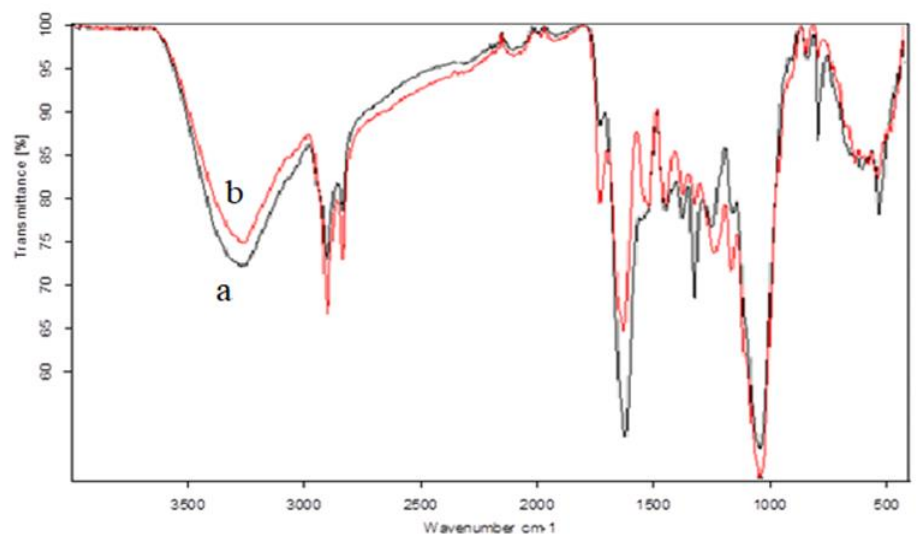

\section{Şekil 3.2. MCY biyokütlesinin FT-IR spektrumlarl (a)yüksüz} (b)boyarmadde yüklü

Şekil 3.2'de 3287-3312 $\mathrm{cm}^{-1}$ aralığında O-H ve N-H gerilim titreşim pikleri, $2849-2917 \mathrm{~cm}^{-1}$ aralığında alifatik zincire bağlı $\mathrm{CH}$ titreşim pikleri, $1619-1730 \mathrm{~cm}^{-1}$ aralığında $\mathrm{C}=\mathrm{O}$ pikleri, $1440-1547 \mathrm{~cm}^{-1}$ aralığında $\mathrm{C}=\mathrm{N}$ ve $\mathrm{C}=\mathrm{C}$ gerilme titreşim pikleri, 1318 ve $1369 \mathrm{~cm}^{-1}$ de C-O gerilme titreşim pikleri ve $1230-1247$ $\mathrm{cm}^{-1}$ aralığında S-O gerilim titreşimine ait pikler kayda değer pikler olarak gözlenmektedir. Boyarmadde biyosorpsiyonundan sonra $-\mathrm{OH}$ ve $-\mathrm{NH}$ gerilme titreşim piklerinde, $\mathrm{C}=\mathrm{O}, \mathrm{C}=\mathrm{N}, \mathrm{C}=\mathrm{C}$ ve S-O gerilme titreşimlerine ait piklerde kaymalar gözlenmiştir. Kaymaların sebebi, MCY yüzeyindeki fonksiyonel gruplar ile 
boyarmadde etkileşimine dayandırılmaktadır. (Jawad ve ark., 2019; Stavrinou ve ark., 2018 ; Naveen ve ark., 2011).

\subsubsection{SEM Analizleri}

Şekil 3.3 ve Şekil 3.5 de HCY ve MCY biyokütlelerinin; Şekil 3.4 ve Şekil 3.6 da ise sırası ile bu biyokütlelerin RR 120 boyarmaddesi ile yüklendikten sonraki taramalı elektron mikroskobu (SEM) görüntüleri verilmiştir.

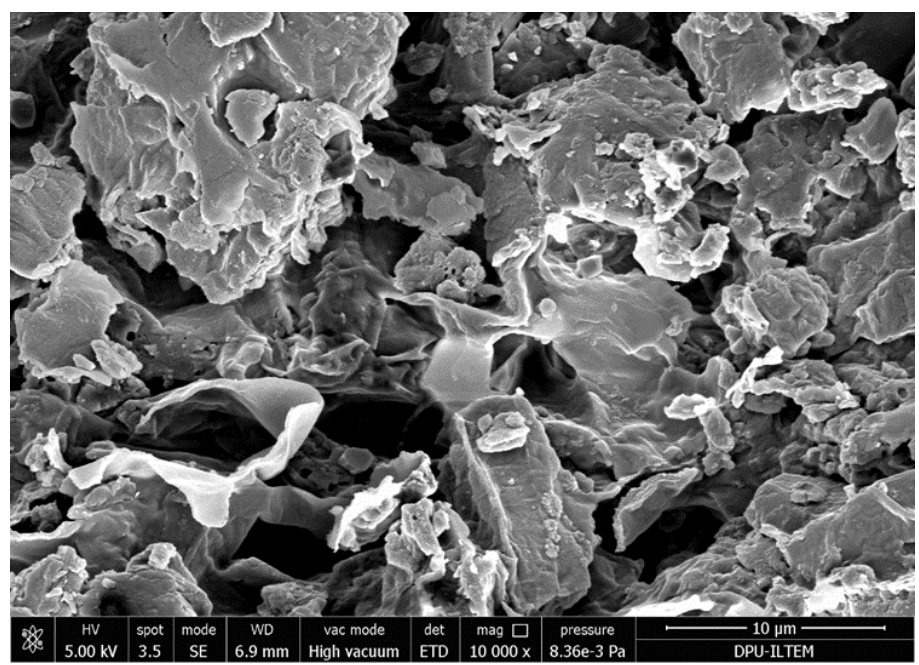

Şekil 3.3. HCY biyokütlesinin biyosorpsiyon öncesi SEM görüntüsü

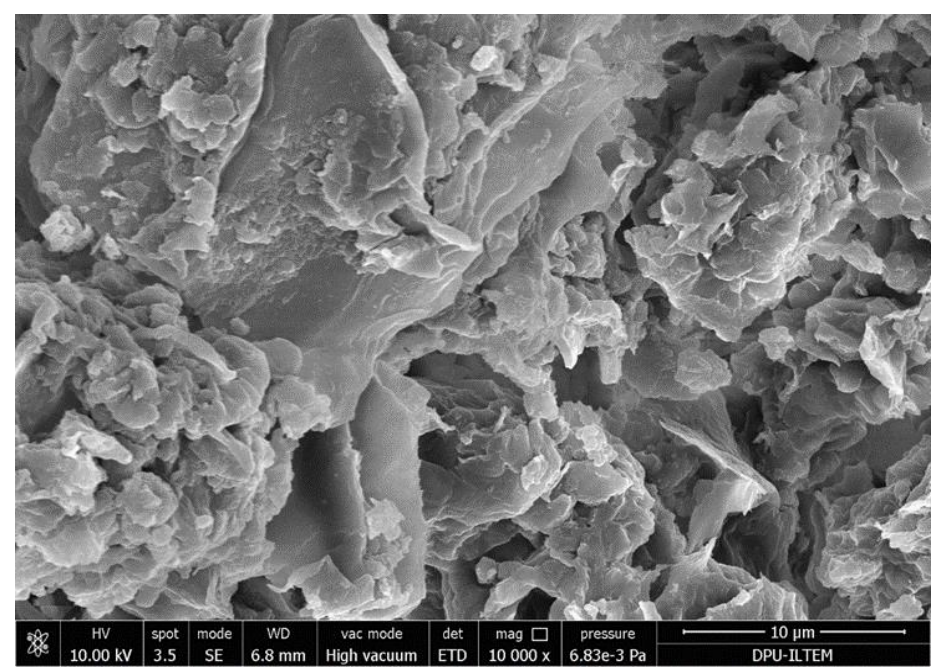

Şekil 3.4. HCY biyokütlesinin RR120 boyarmaddesi ile yüklendikten sonraki SEM görüntüsü

Şekil 3.3 ve Şekil 3.5 de HCY ve MCY biyokütlelerinin boyarmadde biyosorpsiyonundan önce pürüzlü ve değişik büyüklükte gözenekli yüzey yapılarına sahip olduğu gözlenmektedir (Deniz ve Karaman, 2014). Biyosorpsiyondan sonra (Şekil 3.4 ve Şekil 3.6) boyarmaddenin bu gözenekleri doldurması ile her iki biyokütlenin de yüzeyinin daha pürüzsüz bir hal aldığı görülmüştür (Stavrinou ve ark., 2018; Pereira ve ark., 2018; Ahmad ve ark., 2018).

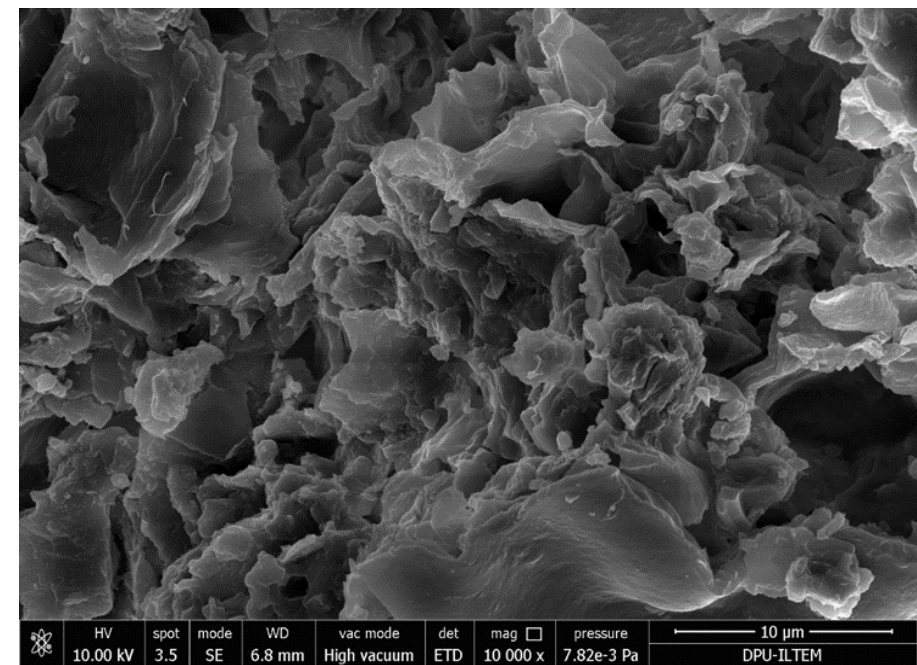

Şekil 3.5. MCY biyokütlesinin biyosorpsiyon öncesi SEM görüntüsü

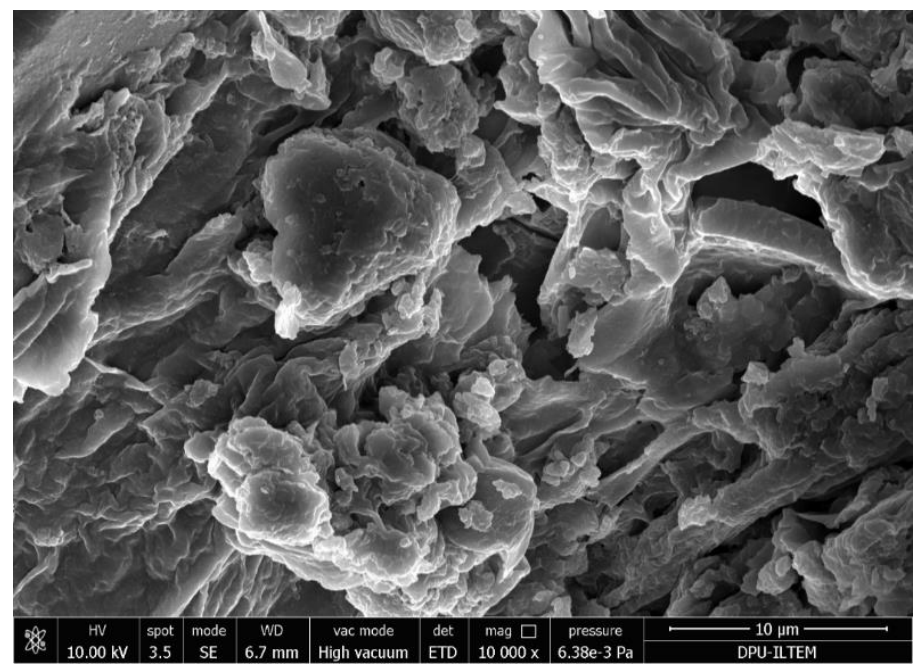

Şekil 3.6. MCY biyokütlesinin RR120 boyarmaddesi ile yüklendikten sonraki SEM görüntüsü

Biyokütlenin modifikasyondan önceki ve sonraki yüzey görüntüleri karşılaştırıldığında ise (şekil 3.3 ve 3.5) biyokütlenin ham halinde kırılmamış yüzeyler gözlenirken modifikasyondan sonra MCY yüzeyinde oluşmuş yarıklar ve küresel boşluklar dikkat çekmektedir. Bu yarıklar ve boşluklar toplam yüzey alanını arttırmakta ve boyarmadde gideriminde ve biyosorpsiyon kapasitesini arttırmakta etken rol oynamaktadır (Çelekli ve ark., 2019).

\subsubsection{Zeta Potansiyeli Ölçümleri}

HCY ve MCY biyokütlelerinin zeta potansiyelleri sirasıyla $-20,7 \mathrm{mV}$ ve $-14,1 \mathrm{mV}$ olarak ölçülmüştür. Bu değerler, ham biyokütlenin sitrik asit ile muamele edilmesinden sonra elde edilen MCY biyokütlesinin yüzey yükünün arttığını ve dolayısıyla modifikasyonun başarılı bir şekilde gerçekleştirildiğini doğrulamıştır (Zhong ve ark., 2011). HCY üzerine RR120 biyosorpsiyonundan sonra HCY nin -20,7 mV olan zeta potansiyeli $-21,5 \mathrm{mV}$ değerine; MCY nin $-14,1 \mathrm{mV}$ olan zeta potansiyel değeri ise $-17,5 \mathrm{mV}$ değerine düşmüştür. RR120 boyarmaddesi yüzeyinde 6 tane $\mathrm{SO}_{3}{ }^{-}$grubu içeren anyonik bir boyarmaddedir (Ayachi ve ark., 2019). Biyosorpsiyondan sonra bu fonksiyonel grupların biyokütle yüzeyinde yer almasından dolayı yüzey yükleri azalmış ve biyosorpsiyonun gerçekleştiği kanıtlanmıştır (Ay ve ark., 2012). 


\subsection{Biyosorpsiyon Deneylerinin Yapılışı}

\subsection{1. pH Etkisi}

pH etkisi biyosorpsiyon deneylerinde çalışılan en önemli parametrelerden biridir. Tane boyutu $250 \mu \mathrm{m}$ ' de sabit tutularak pH 1-9 aralığında değiştirilmiş ve pH'ın biyosorpsiyon verimine etkisi incelenmiștir.

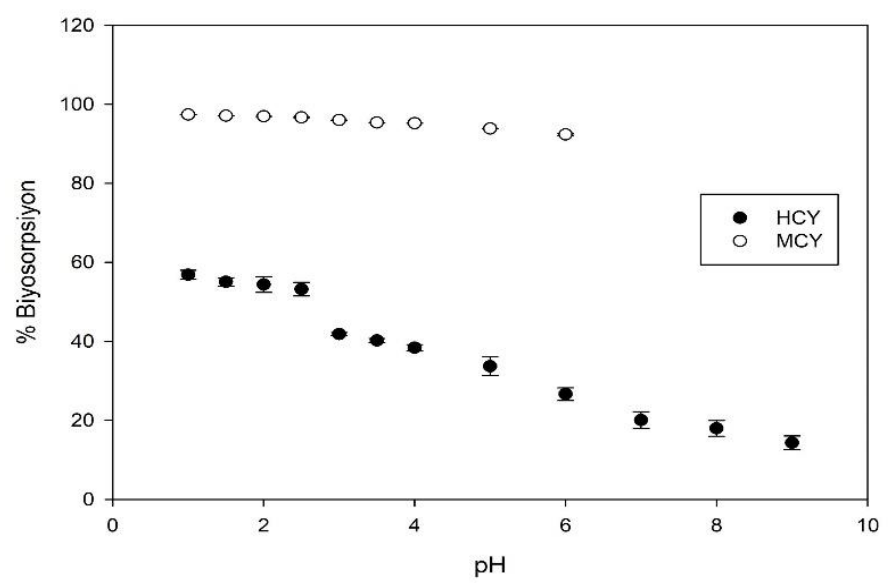

Şekil 3.7. RR120 boyarmaddesinin oda sicaklığında HCY ve $M C Y$ biyokütleleri üzerine adsorpsiyonunda $\mathrm{pH}$ 'ın etkisi (tane boyutu $=250 \mu \mathrm{m}, \mathrm{m}=1 \mathrm{~g} / \mathrm{L}, \mathrm{RR} 120$ derişimi $=100 \mathrm{mg} / \mathrm{L}, V=50$ $m L, t=60 \mathrm{dk}, k . h .=500 \mathrm{rpm})$.

Şekil 3.7'de RR120 boyarmaddesinin HCY ve MCY biyokütleleri üzerine biyosorpsiyonunda $\mathrm{pH}$ 'ın etkisi incelenmiştir. Her iki biyokütle için de, artan $\mathrm{pH}$ değerleri ile biyosorpsiyon veriminin azaldığı gözlenmektedir. En yüksek biyosorpsiyon verimine $\mathrm{pH}=1$ de ulaşı1mıştır. $\mathrm{Bu} \mathrm{pH}$ değerinde, HCY için \%56,83 olan verim, modifikasyon işleminden sonra elde edilen MCY biyokütlesi için \%97,38 değerine yükselmiştir. Modifikasyondan sonra gözlenen biyosorpsiyon kapasitesindeki bu artışı, MCY'nin yüzey elektrik yükündeki zeta potansiyeli değişimi ile açıklamak mümkündür (Cao ve ark., 2014). Juglans Regia L. yaprağının ham ve modifiye yüzeyindeki amin, hidroksil, karboksil ve karbonil gibi çeşitli fonksiyonel gruplar çözelti pH'ından etkilenir(Dawood and Sen, 2012; Mall ve ark., 2006). Düşük pH'll çözeltiler yüksek konsantrasyonda pozitif yüklü hidrojen iyonları içerirler. Yüzeydeki bu fonksiyonel grupların protonlanmasının ardından pozitif yüklü bu gruplar ile RR120 boyarmaddesinin sülfonat grupları arasında elektrostatik etkileşim meydana gelir. $\mathrm{Bu}$ etkileşim sonucu boyarmadde başarılı bir şekilde uzaklaştırılabilmiştir. Sitrik asitle modifikasyondan sonra giderim veriminin artması, sitrik asidin yapısında yer alan karboksil gruplarından kaynaklanmaktadır. Böylece protonlanan grup sayısı ve dolayısıyla giderim verimi artmıştır. Eşitlik 3.1 de ham ve modifiye Juglans Regia L. yaprağından oluşan biyokütlelerin yüzeyindeki (BY) amin gruplarının protonlanması ile boyarmadde arasında gerçekleşen elektrostatik etkileşim gösterilmiştir (Wang ve ark., 2010):

$\mathrm{BY}-\mathrm{NH}_{2}+\mathrm{NaSO}_{3}-\mathrm{RR} 120+\mathrm{HCl} \rightarrow \mathrm{BY}-\mathrm{NH}_{3}{ }^{+}-\mathrm{O}_{3} \mathrm{~S}^{-}-\mathrm{RR} 120$ $+\mathrm{NaCl}$

Eşitlik 3.2 ve Eşitlik 3.3 de ise ham ve modifiye biyokütlelerin yüzeyindeki hidroksil gruplarının (BY-OH) RR120 boyarmaddesi ile etkileşiminin $\mathrm{pH}$ ile nasıl değiştiği görülmektedir. (Eş.3.2)

$$
\begin{aligned}
& \mathrm{BY}-\mathrm{OH} \stackrel{\mathrm{H}^{+}}{\longrightarrow} \mathrm{BY}-\mathrm{OH}_{2}{ }^{+}+\mathrm{RR} 120-\mathrm{SO}_{3}{ }^{-} \rightarrow \\
& \mathrm{BY}-\mathrm{OH}_{2}^{+} \text {) }{ }^{---} \text {( RR120- } \mathrm{SO}_{3}^{-} \\
& \mathrm{BY}-\mathrm{OH} \stackrel{\mathrm{OH}^{-}}{\longrightarrow} \mathrm{BY}-\mathrm{O}^{-}+\mathrm{RR} 120-\mathrm{SO}_{3}^{-}+\mathrm{H}_{2} \mathrm{O} \rightarrow
\end{aligned}
$$

Düşük pH' larda pozitif yüklü BY negatif yüklü RR120 ile etkileşime girerek boyarmadde giderimini sağlamaktadır. Yüksek pH'larda ortamda bol miktarda $\mathrm{OH}^{-}$iyonları bulunmakta ve bu iyonlar ile RR120 molekülleri arasında meydana gelen iyonik itmeler daha düşük biyosorpsiyon yüzdesine neden olmaktadır (Aksu ve Akın, 2010; Akar ve ark., 2011; Aksakal ve Ucun, 2010).

\subsubsection{Biyosorban Miktarının Etkisi}

Biyosorban miktarı RR120'nin sulu çözeltiden biyosorpsiyonunda önemli rol oynayan bir diğer etmendir. Deneyler farklı biyosorban miktarları $(0,5,1,0,2,0,4,0,6,0,8,0$, $10,0 \mathrm{~g} / \mathrm{L})$ ile $\mathrm{pH}=1$ de sabit başlangıç RR120 konsantrasyonunda (100 mg/L) gerçekleştirilmiştir. Şekil 3.8'de biyosorban miktarındaki değişimin biyosorpsiyon verimi üzerine etkisi gösterilmiştir. RR120'nin HCY ile giderim verimi biyosorban miktarı 0,5 ten $10,0 \mathrm{~g} / \mathrm{L}$ ye değiştikçe, $\% 41,04$ den $\% 94,70$ e artmıştır. MCY ile giderim verimi ise artan biyosorban miktarı ile $\% 97,14$ den \%97,62 ye değişmiştir. Bu durum biyosorban miktarı arttıkça, biyosorpsiyon için gerekli yüzey alanının ve aktif bağlanma bölgelerinin sayısının artması ile açıklanabilir (Fiorentin ve ark., 2010; Gupta ve ark., 2010; Çelekli ve ark., 2012). Her iki biyokütle için de biyosorpsiyon verimi belirli bir miktara kadar hızla artarken, bu miktarlardan sonra kaydadeğer bir artış gözlenmemiş ve hemen hemen sabit kalmıştır. Belirli bir konsantrasyondan sonra biyosorban miktarını artırmak, kısmi topaklanmalara sebep olmakta, bu durum da biyosorpsiyon için gerekli bölgelerin sayısını düşürerek \% giderim miktarının sabitlenmesine neden olmaktadır (Cardoso ve ark., 2011; Çelekli ve ark., 2012). Çalışmada, bu sebeplerle HCY ve MCY için optium biyosorban miktarları sırasıyla $6,0 \mathrm{~g} / \mathrm{L}$ ve $4,0 \mathrm{~g} / \mathrm{L}$ olarak belirlenmiş ve tüm deneylerde bu şekilde kullanılmıştır. $\mathrm{Bu}$ miktarlara karşılık gelen giderim verimleri ise \%92,4 ve \% 97,6 dir.

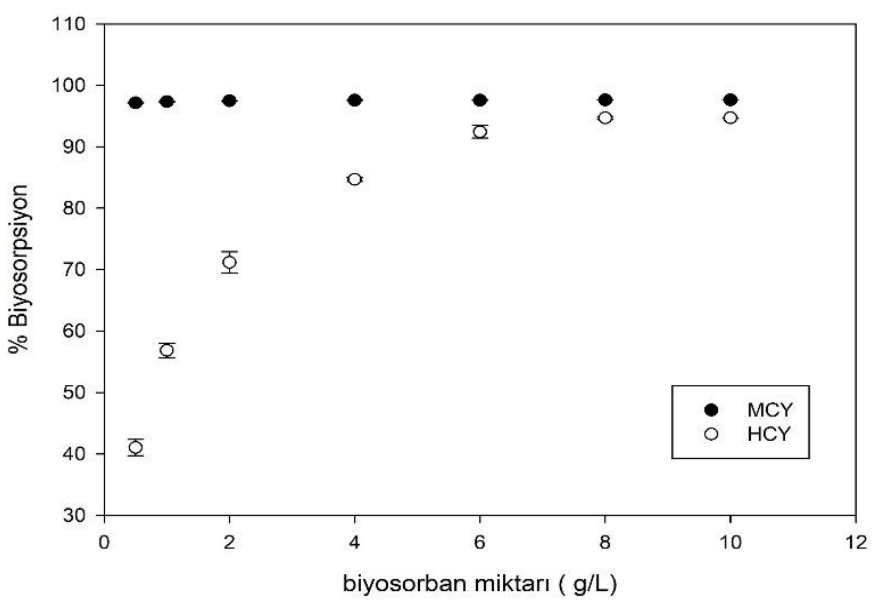

Şekil 3.8. RR120 boyarmaddesinin oda sicaklığında HCY ve MCY biyokütlesi üzerine adsorpsiyonunda biyosorban miktarının etkisi $(\mathrm{pH}=1, \mathrm{RR} 120$ derişimi $=100 \mathrm{mg} / \mathrm{L}, V=50 \mathrm{~mL}$, $t=60 \mathrm{dk}, \mathrm{k} . \mathrm{h} .=500 \mathrm{rpm}$ ). 


\subsubsection{Temas Süresi ve Sicaklı̆̆ın Etkisi}

RR120 boyarmaddesinin ham ve modifiye JUGLANS $R E G \dot{I} A$ L. yaprağı üzerine biyosorpsiyonunda temas süresi ve sıcaklığın etkisi araştırılmıştır. Temas süresi 5-180 dakika zaman aralığında değiştirilmiş olup; $20,30,40$ ve $50^{\circ} \mathrm{C}$ olmak üzere 4 farklı sıcaklıkta çalışılmıştır.

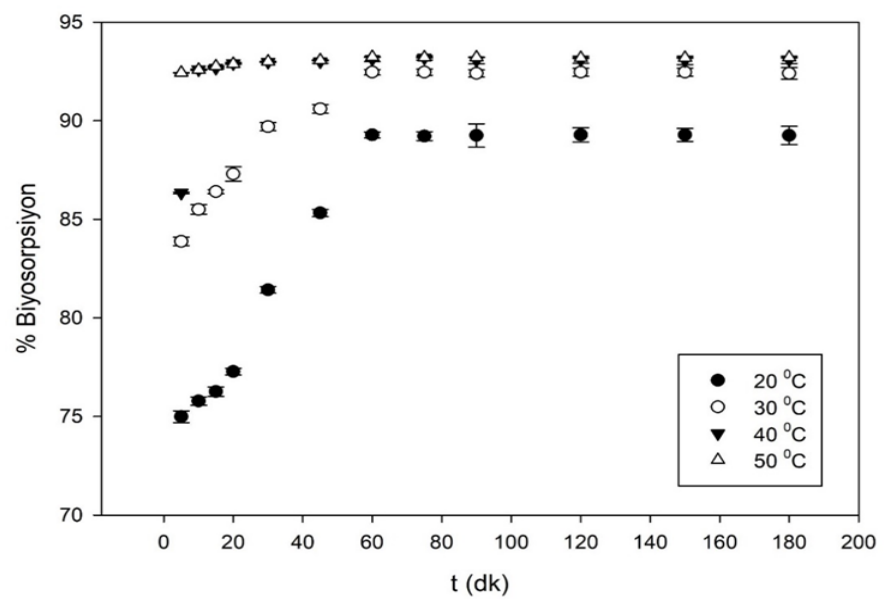

Şekil 3.9. RR120 boyarmaddesinin HCY biyokütlesi üzerine adsorpsiyonunda temas süresi ve sicaklı̆̆ın etkisi ( $p H=1, R R 120$ derişimi $=100 \mathrm{mg} / \mathrm{L}, \mathrm{m}=6 \mathrm{~g} / \mathrm{L}, V=50 \mathrm{~mL}, \mathrm{k.h} .=500 \mathrm{rpm}$ ).

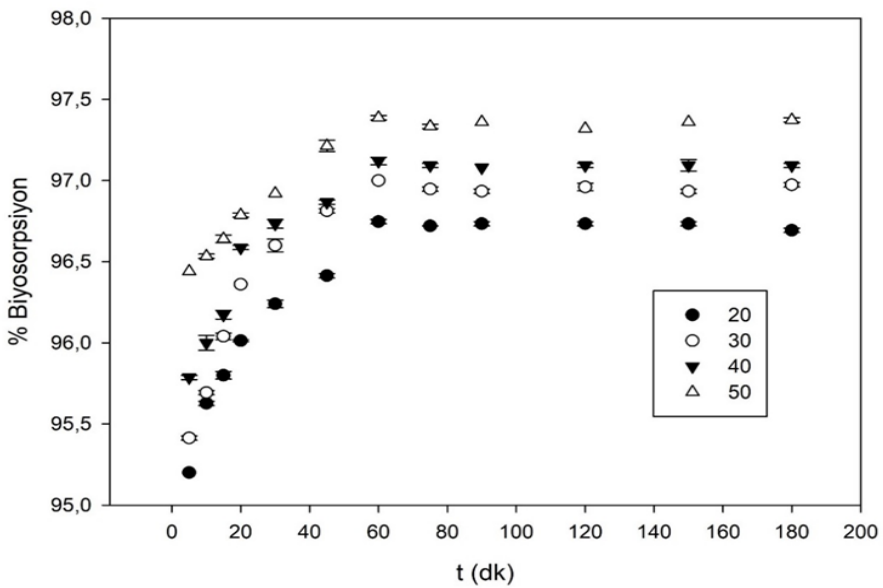

3.10. RR120 boyarmaddesinin MCY biyokütlesi üzerine adsorpsiyonunda temas süresi ve sicakliğın etkisi ( $\mathrm{pH}=1, \mathrm{RR} 120$ derişimi $=100 \mathrm{mg} / \mathrm{L}, \mathrm{m}=4 \mathrm{~g} / \mathrm{L}, V=50 \mathrm{~mL}, \mathrm{k} . h .=500 \mathrm{rpm})$.

HCY ve MCY biyokütlelerinin her ikisi için de biyosorpsiyon verimi tüm sıcaklıklarda 60 dakikaya kadar artmış ve bu temas süresinden sonra dengeye ulaşılmıştır. Başlangıçta biyokütlelerin yüzeyindeki aktif bağlanma bölgelerinin boş olması nedeniyle biyosorpsiyon kapasitesi hızlı bir şekilde artış göstermiş, ilerleyen zamanla bölgelerin boyarmadde molekülleri ile dolmasıyla yüzeyde doygunluk oluşmaya başlamış ve kapasitedeki artış azalarak belli bir temas süresinde dengeye ulaşılmıştır (Morosanu ve ark., 2017; Roy and Mondal, 2017) Ayrıca tüm sıcaklıklarda denge temas süresine kadar kapasitenin artmas1, RR120 boyarmaddesinin bu biyokütleler üzerine olan adsorpsiyonunun hiz kontrollü bir süreç olduğunu göstermektedir (Özcan ve ark., 2007). Ham ve modifiye biyokütlelerin denge adsorpsiyon kapasiteleri artan sicaklıkla birlikte artış göstermektedir. Bu durum RR120 boyarmaddesinin e-ISSN: 2148-2683 kullanılan biyokütleler üzerine adsorpsiyonunun endotermik yapısını ortaya koymaktadır (Özcan ve ark., 2007). Sicaklık 20 ${ }^{\circ} \mathrm{C}$ den $50{ }^{\circ} \mathrm{C}$ ye arttırıldığında, biyosorpsiyon kapasiteleri, denge temas süresi olan 60 dakikada HCY için \%89,28 ten \%93,23 ye; MCY için ise \%96,75 den \%97,39'a yükselmiştir. Sıcaklığın artmasına bağlı olarak biyosorpsiyon veriminin $\operatorname{arttığ~} 1$ gözlenmektedir. Bu etki yüksek sicaklıklarda biyokütlelerin adsorpsiyon için daha fazla aktif bağlanma bölgelerine sahip olmasıyla ve boyarmadde molekülleri ile bu bölgeler arasındaki bağların daha güçlü olmasıyla açıklanabilir. Aynı zamanda, yüksek sıcaklık boyarmadde moleküllerinin daha fazla hareketli olmasına neden olmakta, vizkoziteyi düşürmekte ve bunlara bağlı olarak moleküllerin katı yüzeyine olan yakınlığını artırmaktadır (Morosanu ve ark., 2017).

\subsubsection{Biyosorpsiyon Denge Bulgularının Kinetik Modelle İncelenmesi}

RR120 boyarmaddesinin HCY ve MCY biyokütleleri üzerine adsorpsiyon mekanizmasının aydınlatılması için farklı sıcaklıklarda elde edilen deneysel sonuçlara, yalancı-ikinci dereceden kinetik model uygulanmıştır.

$$
\frac{t}{q_{t}}=\frac{1}{k_{2} q_{2}^{2}}+\frac{1}{q_{2}} t
$$

t zaman (dk); $\mathrm{k}_{2}$ yalanc1-ikinci-derece hız sabiti (g/mg dk), $\mathrm{q}_{2}$ maksimum biyosorpsiyon kapasitesi $(\mathrm{mg} / \mathrm{g}), \mathrm{q}_{\mathrm{t}}$ ise herhangi bir $\mathrm{t}$ anındaki biyosorplanan madde miktarıdır (mg/g). $\mathrm{k}_{2}$ ve $\mathrm{q}_{2}$ değerleri t'nin $t / q_{t}$ ye karşı çizilen grafiğinden hesaplanmaktadır(Şekil 3.11 ve Şekil 3.12). Elde edilen kinetik parametreler çizelge 3.1 ve çizelge 3.2 'de verilmiştir.

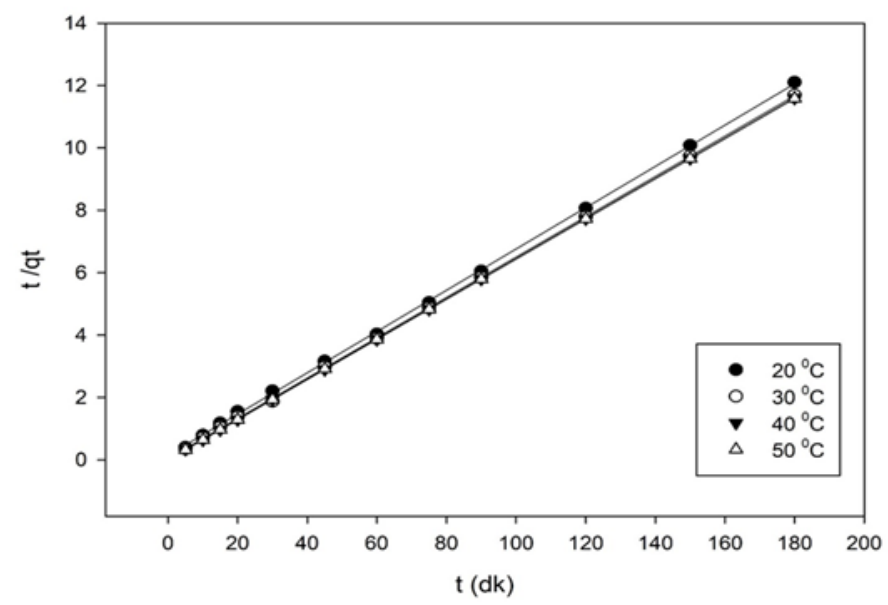

Şekil 3.11. HCY biyokütlesi üzerine RR120 nin farklı sıcaklıklardaki adsorpsiyonunda yalancl-ikinci dereceden biyosorpsiyon kinetiğ $i$ 


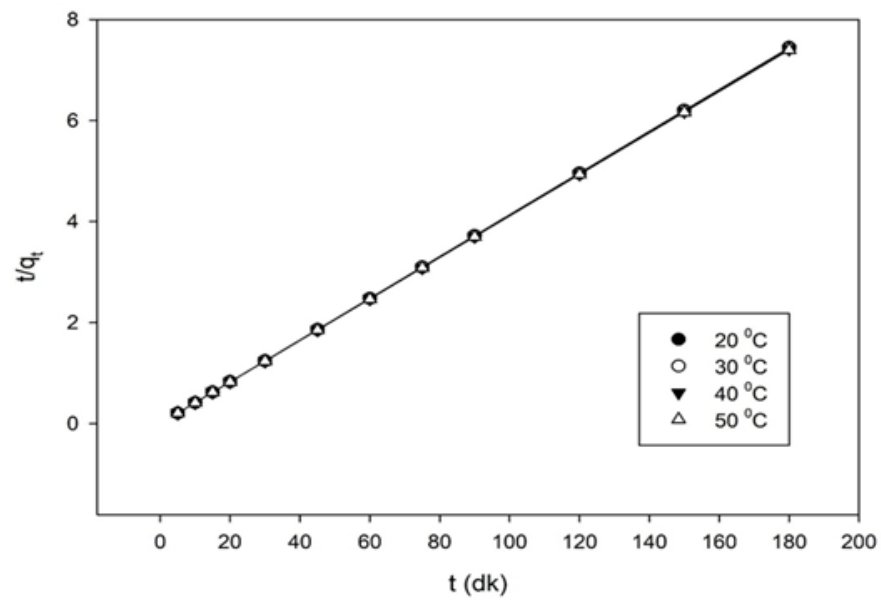

Şekil 3.12 MCY biyokütlesi üzerine RR120 nin farklı sicaklıklardaki adsorpsiyonunda yalancl-ikinci dereceden biyosorpsiyon kinetiği

Çizelge 3.1 RR120 boyarmaddesinin farklı sicaklıklarda HCY biyokütlesi üzerine adsorpsiyonunda yalancl-ikinci dereceden kinetik modele ilişkin parametreler

\begin{tabular}{cccc}
\hline HCY & $\mathrm{k}_{2}(\mathrm{~g} / \mathrm{mg} \mathrm{dk})$ & $\mathrm{q}_{2}(\mathrm{mg} / \mathrm{g})$ & $\mathrm{r}^{2}$ \\
\hline $20{ }^{0} \mathrm{C}$ & 0,0299 & 15,1174 & 0,9998 \\
$30{ }^{\circ} \mathrm{C}$ & 0,1101 & 15,4750 & 0,9999 \\
$40{ }^{\circ} \mathrm{C}$ & 0,5524 & 15,5281 & 0,9999 \\
$50{ }^{\circ} \mathrm{C}$ & 0,7700 & 15,5417 & 0,9999 \\
\hline
\end{tabular}

Çizelge 3.2 RR120 boyarmaddesinin farklı slcaklıklarda MCY biyokütlesi üzerine adsorpsiyonunda yalancı-ikinci dereceden kinetik modele ilişkin parametreler

\begin{tabular}{cccc}
\hline MCY & $\mathrm{k}_{2}(\mathrm{~g} / \mathrm{mg} \mathrm{dk})$ & $\mathrm{q}_{2}(\mathrm{mg} / \mathrm{g})$ & $\mathrm{r}^{2}$ \\
\hline $20{ }^{0} \mathrm{C}$ & 0,3500 & 24,1972 & 0,9999 \\
$30{ }^{\circ} \mathrm{C}$ & 0,3834 & 24,2566 & 0,9999 \\
$40{ }^{\circ} \mathrm{C}$ & 0,4026 & 24,2887 & 0,9999 \\
$50{ }^{\circ} \mathrm{C}$ & 0,4404 & 24,3549 & 0,9999 \\
\hline
\end{tabular}

Deneysel sonuçlar, RR120 nin HCY ve MCY biyokütleleri ile biyosorpsiyonunun, çalışılan tüm sıcaklıklarda yüksek korelasyon katsayısı $\left(\mathrm{r}^{2}\right)$ değerleri ile yalanc1-ikinci dereceden kinetik modele uyduğunu göstermiştir. Yalanc1-ikinci derceden hız sabitleri, sıcaklık $20{ }^{\circ} \mathrm{C}$ den $50{ }^{\circ} \mathrm{C}$ ye arttıkça HCY için 0,0299 dan $0,7700 \mathrm{~g} / \mathrm{mg}$ dk değerine; MCY için ise $0,3500 \mathrm{den}$ $0,4404 \mathrm{~g} / \mathrm{mg}$ dk değerine düzenli bir artış sağlamıştır. Bu durum RR120 boyarmaddesinin, bu biyokütleler üzerine adsorpsiyonunun hiz kontrollü bir süreç olduğunu ispatlamaktadır (Özcan ve ark., 2007).

\subsubsection{Biyosorpsiyon İotermleri}

$\mathrm{Bu}$ çalışmada RR120 boyarmaddesinin HCY ve MCY biyokütleleri üzerine biyosorpsiyonun denge karakteristiklerini açıklamak için Langmuir (Eş. 3.5) ve Freundlich (Eş. 3.6) lineer izoterm model eşitlikleri kullanılmıştır.

$$
\begin{aligned}
& \frac{C_{e}}{q_{e}}=\frac{1}{\left(q_{\max } K_{L}\right)}+\frac{C_{e}}{q_{\max }} \\
& \ln q_{e}=\ln K_{F}+\frac{1}{n} \ln C_{e}
\end{aligned}
$$

Eşitliklerde yer alan $\mathrm{q}_{\max }$ maksimum biyosorpsiyon miktarını (mg/g), $\mathrm{q}_{\mathrm{e}}$ denge biyosorpsiyon kapasitesini (mg/g), $\mathrm{C}_{\mathrm{e}}$ denge çözelti konsantrasyonunu $(\mathrm{mg} / \mathrm{L}), \mathrm{K}_{\mathrm{L}}$ ise biyosorpsiyon serbest enerjisi ile ilişkili olan Langmuir biyosorpsiyon sabitini $(\mathrm{L} / \mathrm{mg})$ ifade etmektedir. $\mathrm{K}_{\mathrm{F}}(\mathrm{L} / \mathrm{g})$ ve $\mathrm{n}$ ise Freindlich izoterm sabitleridir. $\mathrm{K}_{\mathrm{F}}$, biyosorpsiyon kapasitesini gösterir ve değeri ne kadar büyükse kapasite o kadar yüksektir. n (birimsiz), heterojenite faktörüdür.

Şekil 3.13 ve Şekil 3.14 ' de sirasıyla ham ve modifiye biyokütleler için farklı sıcaklıklarda Langmuir izoterm modeline ait grafikler çizdirilerek korelasyon katsayısı $\left(r^{2}\right)$ değerleri bulunmuştur. Söz konusu grafiklerden hesaplanan $\mathrm{K}_{\mathrm{L}}, \mathrm{R}_{\mathrm{L}}$ ve $\mathrm{q}_{\max }$ değerleri Çizelge 3.3 ve Çizelge 3.4' de verilmiştir.

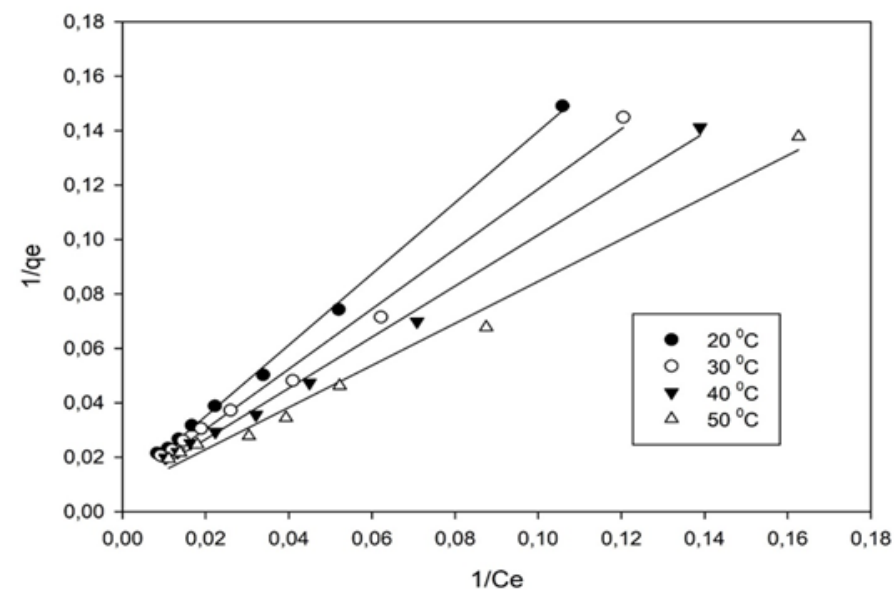

Şekil 3.13 RR120 nin HCY biyokütlesi üzerine adsorpsiyonunda Langmuir izoterm grafiği.

Langmuir izotermi, adsorpsiyonun hem yapı hem de enerji bakımından homojen aktif bağlanma bölgelerinde meydana geldiğini varsayarak, biyosorbanın diş yüzeyinde oluşan tek tabakalı tutunmayı açıklamaya çalışır (Munagapati ve ark., 2019). 


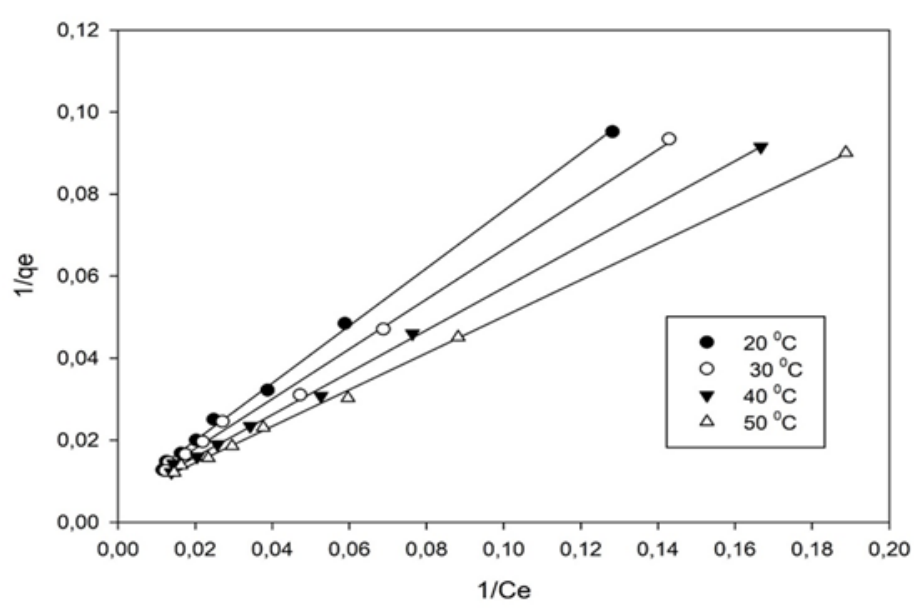

Şekil 3.14 RR120 nin MCY biyokütlesi üzerine adsorpsiyonunda Langmuir izoterm grafiği.

Çizelge3.3 Farklı sicakliklarda RR120 boyarmaddesinin HCY biyokütlesi üzerine adsorpsiyonunda Langmuir izoterm sabitleri.

\begin{tabular}{ccccc}
\hline $\mathrm{HCY}$ & $\mathrm{K}_{\mathrm{L}}(\mathrm{L} / \mathrm{mg})$ & $\mathrm{q}_{\max }(\mathrm{mg} / \mathrm{g})$ & $\mathrm{r}_{\mathrm{L}}{ }^{2}$ & $\mathrm{R}_{\mathrm{L}}$ \\
\hline $20{ }^{\circ} \mathrm{C}$ & $6,76 \times 10^{-3}$ & 113,01 & 0,9982 & 0,270 \\
$30{ }^{\circ} \mathrm{C}$ & $7,51 \times 10^{-3}$ & 120,71 & 0,9933 & 0,2498 \\
$40{ }^{\circ} \mathrm{C}$ & $8,32 \times 10^{-3}$ & 128,06 & 0,9954 & 0,2311 \\
$50{ }^{\circ} \mathrm{C}$ & $9,59 \times 10^{-3}$ & 135,16 & 0,9879 & 0,2068 \\
\hline
\end{tabular}

Çizelge3.4 Farklı sıcakliklarda RR120

boyarmaddesinin MCY biyokütlesi üzerine adsorpsiyonunda Langmuir izoterm sabitleri.

\begin{tabular}{lcccc}
\hline $\mathrm{HCY}$ & $\mathrm{K}_{\mathrm{L}}(\mathrm{L} / \mathrm{mg})$ & $\mathrm{q}_{\max }(\mathrm{mg} / \mathrm{g})$ & $\mathrm{r}_{\mathrm{L}}{ }^{2}$ & $\mathrm{R}_{\mathrm{L}}$ \\
\hline $20{ }^{\circ} \mathrm{C}$ & $8,43 \times 10^{-3}$ & 169,45 & 0,9985 & 0,2287 \\
$30{ }^{\circ} \mathrm{C}$ & $9,50 \times 10^{-3}$ & 173,28 & 0,9963 & 0,2083 \\
$40{ }^{\circ} \mathrm{C}$ & $1,08 \times 10^{-2}$ & 178,86 & 0,9986 & 0,1880 \\
$50{ }^{\circ} \mathrm{C}$ & $1,24 \times 10^{-2}$ & 181,21 & 0,9988 & 0,1678 \\
\hline
\end{tabular}

Tek tabakalı RR120 biyosorpsiyonu, artan sıcaklıkla artış göstermiş ve $50{ }^{\circ} \mathrm{C}$ de $\mathrm{HCY}$ için maksimum 135,16 mg/g değerine, MCY için ise maksimum 181,21 mg/g değerine ulaşmıştır. $\mathrm{Bu}$ durum, RR120 nin $\mathrm{HCY}$ ve MCY üzerine biyosorpsiyon prosesinin endotermik yapısını göstermektedir (Zhong ve ark., 2011).

Langmuir izotermi aynı zamanda birimsiz bir sabit olan $\mathrm{R}_{\mathrm{L}}$ yardımıyla da açıklanabilir. $\mathrm{R}_{\mathrm{L}}$ ayırma faktörü veya denge parametresi olarak da bilinir. Biyosorpsiyon prosesinin kendiliğinden gerçekleşip gerçekleşmediği konusunda bilgi verir. Aşağıdaki eşitlik yardımıyla hesaplanır.

$$
R_{L}=\frac{1}{1+K_{L} C_{o}}
$$

Eşitlikte yer alan $\mathrm{C}_{0}$ başlangıç boyarmadde konsantrasyonunu ifade etmektedir. Her iki biyokütle için de hesaplanan $R_{L}$ değerlerinin 0 ile 1 arasında olması, RR120 nin bu biyokütleler üzerine adsorpsiyonunun istemli olduğunu ifade etmektedir (Kızıltaş, 2021; Munagapati ve ark., 2019; Külcü, 2012).

Şekil 3.15 ve Şekil $3.16^{\prime}$ da sırasıyla ham ve modifiye biyokütleler için farklı sıcaklıklarda Freundlich izoterm modeline ait grafikler çizdirilerek korelasyon katsayısı $\left(\mathrm{r}^{2}\right)$ değerleri bulunmuştur. Söz konusu grafiklerden hesaplanan $\mathrm{K}_{\mathrm{F}}$ ve $n$ değerleri Çizelge 3.5 ve Çizelge 3.6' da verilmiştir

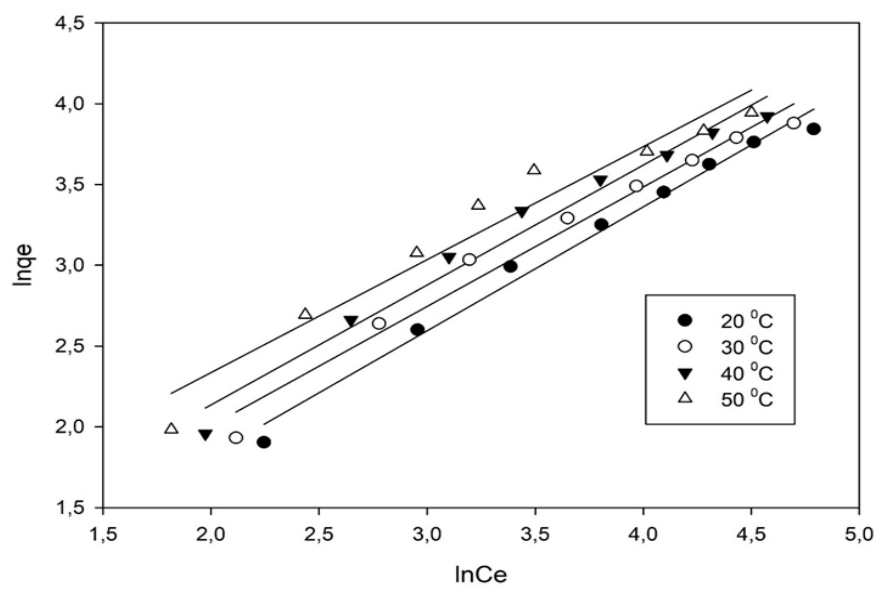

3.15 RR120 nin HCY biyokütlesi üzerine adsorpsiyonunda Freundlich izoterm grafiği.

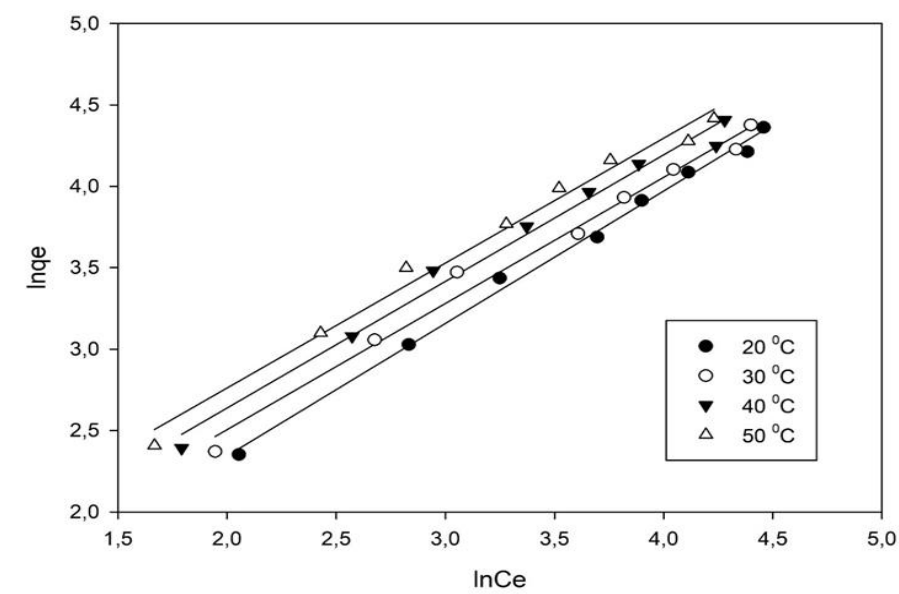

Şekil 3.16 RR120 nin MCY biyokütlesi üzerine adsorpsiyonunda Freundlich izoterm grafiği. 
Çizelge 3.5 Farkl slcaklıklarda RR120 boyarmaddesinin HCY biyokütlesi üzerine adsorpsiyonunda Freundlich izoterm sabitleri.

\begin{tabular}{cccc}
\hline $\mathrm{HCY}$ & $\mathrm{K}_{\mathrm{F}}(\mathrm{L} / \mathrm{g})$ & $\mathrm{n}$ & $\mathrm{r}^{2}$ \\
\hline $20^{\circ} \mathrm{C}$ & 1,3387 & 1,3034 & 0,9861 \\
$30^{\circ} \mathrm{C}$ & 1,6943 & 1,3529 & 0,9772 \\
$40{ }^{\circ} \mathrm{C}$ & 1,9190 & 1,3480 & 0,9760 \\
$50{ }^{\circ} \mathrm{C}$ & 2,5530 & 1,4306 & 0,9483 \\
\hline
\end{tabular}

Çizelge 3.6 Farklı sicaklıklarda RR120 boyarmaddesinin MCY biyokütlesi üzerine adsorpsiyonunda Freundlich izoterm sabitleri.

\begin{tabular}{cccc}
\hline $\mathrm{HCY}$ & $\mathrm{K}_{\mathrm{F}}(\mathrm{L} / \mathrm{g})$ & $\mathrm{n}$ & $\mathrm{r}^{2}$ \\
\hline $20{ }^{\circ} \mathrm{C}$ & 2,0493 & 1,2295 & 0,9954 \\
$30^{\circ} \mathrm{C}$ & 2,5966 & 1,2901 & 0,9868 \\
$40{ }^{\circ} \mathrm{C}$ & 2,9558 & 1,2865 & 0,9871 \\
$50{ }^{\circ} \mathrm{C}$ & 3,4077 & 1,3034 & 0,9867
\end{tabular}

Freundlich izoterm modeli çok katmanlı biyosorpsiyonu açıklar. Biyokütle yüzeyinde biyosorpsiyon 1sısı ve adsorsorpsiyon bölgelerinin homojen olmayan dağılımları söz konusudur ve adsorbe olmuş moleküller arasında etkileşim vardır (Stavrinou ve ark., 2018; Foo and Hameed, 2012). Ayrica Freundlich hız sabiti olan $\mathrm{K}_{\mathrm{F}}$ değerinin yüksek olmas1, yüksek adsorpsiyon kapasitesine işaret etmektedir (Peraira ve ark., 2018; Kale, 2019). HCY için 2,55 L/g; MCY için ise 3,40 L/g KF değerlerine ulaşılmıştır. $\mathrm{n}$ değeri ise adsorpsiyon bölgelerinin heterojenlik derecesi hakkında bilgi verir. $\mathrm{n}$ sıfıra yaklaştıkça yüzeydeki bu bölgelerin heterojenliği artar, $\mathrm{n}$ değerinin birden büyük olması ise adsorpsiyonun uygunluğuna işaret etmektedir (Özcan, 2005; Khan Rao ve Khan, 2009). RR120'nin HCY ve MCY üzerine biyosorpsiyonunda elde edilen maksimum $n$ değerleri sırasıyla 1,43 ve 1,30 olup bu durum bu biyokütlelerin RR120 adsorpsiyonu için uygun olduğunu göstermektedir.

Deneysel sonuçların Langmuir ve Freundlich izoterm modellerine uygulanmasıyla elde edilen grafiklerin $r^{2}$ değerleri karşılaştırıldığında, RR120 nin HCY ve MCY biyokütleleri üzerine adsorpsiyonunun, Langmuir izoterm modeline daha iyi uyum sağladığı gözlemlenmiştir.

\section{Sonuç}

Bu çalışmada RR120 boyarmaddesinin JUGLANS REGİA L. yaprağı üzerine sulu çözeltiden biyosorpsiyonunda, biyosorpsiyon kapasitesini artırmak için biyokütlenin sitrik asit ile modifikasyonu araştırılmıştır. Deneyler $\mathrm{pH}$, biyosorban miktarı, temas süresi ve sıcaklığın fonksiyonu olarak karşılaştırmalı olarak gerçekleştirilmiştir. Maksimum biyosorpsiyon kapasitesine ham ve modifiye biyokütlelerin her ikisi için de $\mathrm{pH} 1$ değerinde ulaşılmıştır. Optimum biyokütle miktarı HCY için $6 \mathrm{gL}^{-1}$ olarak tespit edilirken $\mathrm{MCY}$ için $4 \mathrm{gL}^{-1}$ olarak bulunmuştur. Biyosorpsiyon kinetiği en iyi yalanc1-ikinci dereceden kinetik modelle açıklanmıştır. Biyosorpsiyon dengesini açıklamak için Langmuir ve Freundlich izoterm modelleri kullanılmış ve denge verilerinin çalışılan konsantrasyon aralığında ve seçilen tüm sıcaklıklarda Langmuir izoterm modeline daha iyi uyum sağladığı bulunmuştur. Buradan elde edilen tek tabakalı maksimum adsorpsiyon kapasitesi 50 ${ }^{\circ} \mathrm{C}$ 'de HCY için 135,16 mg/g ;MCY için ise 181,21 mg/g olarak tespit edilmiştir.

Sonuç olarak, ham ve modifiye JUGLANS REGIA L. yaprağı atık sulardan boyarmadde gideriminde kullanılabilecek, ucuz, bol ve yerel olarak ulaşlabilecek alternatif bir biyosorbenttir. Modifikasyon biyosorpsiyon kapasitesini önemli miktarda arttırmıştır.

\section{Kaynakça}

Ahmad, S., Wong, Y. C. \& Veloo, K. V. (2018, April). Sugarcane bagasse powder as biosorbent for reactive red 120 removals from aqueous solution. In $I O P$ Conference Series: Earth and Environmental Science 140(1) 120-27.

Akar, S. T., Gorgulu, A., Akar, T. \& Celik, S. (2011). Decolorization of Reactive Blue 49 contaminated solutions by Capsicum annuum seeds: Batch and continuous mode biosorption applications. Chemical Engineering Journal, 168(1), 125-133.

Aksakal, O. \& Ucun, H. (2010). Equilibrium, kinetic and thermodynamic studies of the biosorption of textile dye (Reactive Red 195) onto Pinus sylvestris L. Journal of Hazardous Materials, 181(1-3), 666-672.

Aksu, Z. \& Akın, A. B. (2010). Comparison of Remazol Black B biosorptive properties of live and treated activated sludge. Chemical Engineering Journal, 165(1), 184-193.

Ay, Ç. Ö., Özcan, A. S., Erdoğan, Y. \& Özcan, A. (2012). Characterization of Punica granatum L. peels and quantitatively determination of its biosorption behavior towards lead (II) ions and Acid Blue 40. Colloids and Surfaces B: Biointerfaces, 100, 197-204

Ayachi, F., Lima, E. C., Sakly, A., Mejri, H. \& Lamine, A. B. (2019). Modeling of adsorption isotherms of reactive red RR-120 on spirulina platensis by statistical physics formalism involving interaction effect between adsorbate molecules. Progress in Biophysics and Molecular Biology, 141, 47-59.

Bayramoğlu, G., Çelik, G. \& Arica, M. Y. (2006). Studies on accumulation of uranium by fungus Lentinus sajorcaju. Journal of Hazardous Materials, 136(2), 345-353.

Bulgariu, L., Escudero, L. B., Bello, O. S., Iqbal, M., Nisar, J., Adegoke, K. A. \& Anastopoulos, I. (2019). The utilization of leaf-based adsorbents for dyes removal: A review. Journal of Molecular Liquids, 276, 728-747.

Cao, J. S., Lin, J. X., Fang, F., Zhang, M. T. \& Hu, Z. R. (2014). A new absorbent by modifying walnut shell for the removal of anionic dye: kinetic and thermodynamic studies. Bioresource Technology, 163, 199-205.

Cardoso, N. F., Lima, E. C., Pinto, I. S., Amavisca, C. V., Royer, B., Pinto, R. B. \& Pereira, S. F. (2011). Application of cupuassu shell as biosorbent for the removal of textile dyes from aqueous solution. Journal of Environmental Management, 92(4), 1237-1247. 
Chaleshtori, A. N., Meghadddam, F. M., Sadeghi, M., Rahimi, R., Hemati, S. \& Ahmadi, A. (2017). Removal of Acid Red 18 (Azo-Dye) from aqueous solution by adsorption onto activated charcoal prepared from almond shell. Journal of Environmental Science and Management, 20(2).

Çelekli, A., Bozkuş, B. \& Bozkurt, H. (2019). Development of a new adsorbent from pumpkin husk by $\mathrm{KOH}$-modification to remove copper ions. Environmental Science and Pollution Research, 26(12), 11514-11523.

Çelekli, A., İlgün, G. \& Bozkurt, H. (2012). Sorption equilibrium, kinetic, thermodynamic, and desorption studies of Reactive Red 120 on Chara contraria. Chemical Engineering Journal, 191, 228-235.

Dawood, S. \& Sen, T. K. (2012). Removal of anionic dye Congo red from aqueous solution by raw pine and acid-treated pine cone powder as adsorbent: equilibrium, thermodynamic, kinetics, mechanism and process design. Water Research, 46(6), 1933-1946.

Deniz, F. \& Karaman, Ş. (2014). Pinus brutia Ten.(Kızılçam) Kozalak ve Yaprak Biyomasının Boya Biyosorpsiyon/Desorpsiyon Potansiyeli. KSÜ Doğa Bilimleri Dergisi, 17(3), 19-25.

dos Santos, V. C. G., de Toledo Gomes, C. A., Dragunski, D. C., Koslowski, L. A. D. \& Lunelli, K. (2019). Removal of metals ions from aqueous solution using modified sugarcane bagasse. Revista Virtual de Química, 11(4), 1289-1301.

Fiorentin, L. D., Trigueros, D. E., Módenes, A. N., EspinozaQuiñones, F. R., Pereira, N. C., Barros, S. T. \& Santos, O. A. (2010). Biosorption of reactive blue $5 \mathrm{G}$ dye onto drying orange bagasse in batch system: Kinetic and equilibrium modeling. Chemical Engineering Journal, 163(1-2), 68-77.

Foo, K. Y. \& Hameed, B. H. (2012). Preparation, characterization and evaluation of adsorptive properties of orange peel based activated carbon via microwave induced K2CO3 activation. Bioresource Technology, 104, 679-686.

Gupta, V. K., Jain, R. \& Shrivastava, M. (2010). Adsorptive removal of Cyanosine from wastewater using coconut husks. Journal of Colloid and Interface Science, 347(2), 309-314.

Gül, Ü. D. \& Yıldız, Y. Yüzey Aktif Madde ile Modifiye Edilmiş Atık Yer Fistığı Kabuğunun Tekstil Boyası Biyosorpsiyonu Kapasitesinin Belirlenmesi. Türk Tarım ve Doğa Bilimleri Dergisi, 7(3), 533-539.

Jahanban-Esfahlan, A., Jahanban-Esfahlan, R., Tabibiazar, M., Roufegarinejad, L. \& Amarowicz, R. (2020). Recent advances in the use of walnut (Juglans regia L.) shell as a valuable plant-based bio-sorbent for the removal of hazardous materials. RSC Advances, 10(12), 7026-7047.

Jawad, A. H., Mamat, N. H., Hameed, B. H. \& Ismail, K. (2019). Biofilm of cross-linked chitosan-ethylene glycol diglycidyl ether for removal of reactive red 120 and methyl orange: adsorption and mechanism studies. Journal of Environmental Chemical Engineering, 7(2), 102965.

Kale, M. (2019). Biyokütle kullanılarak ă̆ır metal giderimi, Yüksek Lisans Tezi, Kütahya Dumlupınar Üniversitesi, Fen Bilimleri Enstitüsü, Kütahya, 67 s.

Katheresan, V., Kansedo, J. \& Lau, S. Y. (2018). Efficiency of various recent wastewater dye removal methods: a review. Journal of environmental chemical engineering. 6(4), 4676-4697.

Khan Rao, R.A., Khan M.A. (2009). Biosorption of bivalent metal ions from aqueous solution by an agricultural waste:
Kinetics, thermodynamics and environmental effects. Colloids and Surfaces A: Physicochem. Eng. Aspects, 332, 121-128.

Kızıltaş, H. (2021). Orange G'nin Sulu Çözeltilerden Uzaklaştırılması için $\alpha$-Fe2O3 Nanopartiküllerinin Adsorban Olarak Kullanılması; Adsorpsiyon, Kinetik ve Termodinamik Özellikleri. Avrupa Bilim ve Teknoloji Dergisi, 21, 43-52.

Külcü, A. (2012). Metil viyole içeren sulu çözeltilerden renk giderimi için thamnidium elegans' in biyosorpsiyon karaktersitiklerinin incelenmesi, Yüksek Lisans Tezi, Eskişehir Osmangazi Üniversitesi Fen Bilimleri Enstitüsü, Eskişehir, $92 \mathrm{~s}$.

Mall, I. D., Srivastava, V. C. \& Agarwal, N. K. (2006). Removal of Orange-G and Methyl Violet dyes by adsorption onto bagasse fly ash - kinetic study and equilibrium isotherm analyses. Dyes and pigments, 69(3), 210-223.

Morosanu, I., Teodosiu, C., Paduraru, C., Ibanescu, D. \& Tofan, L. (2017). Biosorption of lead ions from aqueous effluents by rapeseed biomass. New Biotechnology, 39, 110-124.

Munagapati, V. S., Wen, J. C., Pan, C. L., Gutha, Y. \& Wen, J. H. (2019). Enhanced adsorption performance of Reactive Red 120 azo dye from aqueous solution using quaternary amine modified orange peel powder. Journal of Molecular Liquids, 285, 375-385.

Naveen, N., Saravanan, P., Baskar, G. \& Renganathan, S. (2011). Equilibrium and kinetic modeling on the removal of Reactive Red 120 using positively charged Hydrilla verticillata. Journal of the Taiwan Institute of Chemical Engineers, 42(3), 463-469.

Özcan, A. S., Özcan, A., Tunali, S., Akar, T., Kiran, I. \& Gedikbey, T. (2007). Adsorption potential of lead (II) ions from aqueous solutions onto Capsicum annuum seeds. Separation Science and Technology, 42(1), 137-151.

Özcan, A., Özcan, A. S., Tunali, S., Akar, T. \& Kiran, I. (2005). Determination of the equilibrium, kinetic and thermodynamic parameters of adsorption of copper (II) ions onto seeds of Capsicum annuum. Journal of Hazardous Materials, 124(1-3), 200-208.

Paul, J., Rawat, K. P., Sarma, K. S. S. \& Sabharwal, S. (2011). Decoloration and degradation of Reactive Red-120 dye by electron beam irradiation in aqueous solution. Applied Radiation and Isotopes, 69(7), 982-987.

Pereira, I. C., Carvalho, K. Q., Passig, F. H., Ferreira, R. C., Rizzo-Domingues, R. C. P., Hoppen, M. I. \& Perretto, F. (2018). Thermal and thermal-acid treated sewage sludge for the removal of dye reactive Red 120: Characteristics, kinetics, isotherms, thermodynamics and response surface methodology design. Journal of Environmental Chemical Engineering, 6(6), 7233-7246.

Roy, T. K. \& Mondal, N. K. (2017). Biosorption of Congo Red from aqueous solution onto burned root of Eichhornia crassipes biomass. Applied Water Science, 7(4), 1841-1854.

Saleh, M., Yalva, M., Arslan, H. \&Gün, M. (2019). Malachite Green Dye Removal from Aqueous Solutions Using Invader Centaurea Solstitialis Plant and Optimization by Response Surface Method: Kinetic, Isotherm, and Thermodynamic Study. Avrupa Bilim ve Teknoloji Dergisi, 17, 755-768.

Smith, J.M. (1982). Chemical Engineering Kinetics. McGraw Hill Book Company, 3, 676 s.

Stavrinou, A., Aggelopoulos, C. A. \& Tsakiroglou, C. D. (2018). Exploring the adsorption mechanisms of cationic and 
anionic dyes onto agricultural waste peels of banana, cucumber and potato: adsorption kinetics and equilibrium isotherms as a tool. Journal of Environmental Chemical Engineering, 6(6), 6958-6970.

Thieman, W.J. \& Palladino, M.A. (2004), Introduction Biotechnology, Pearson, $304 \mathrm{~s}$.

Wang, Z., Xiang, B., Cheng, R. \& Li, Y. (2010). Behaviors and mechanism of acid dyes sorption onto diethylenetriaminemodified native and enzymatic hydrolysis starch. Journal of Hazardous Materials, 183(1-3), 224-232.

Zhong, Q. Q., Yue, Q. Y., Li, Q., Xu, X. \& Gao, B. Y. (2011). Preparation, characterization of modified wheat residue and its utilization for the anionic dye removal. Desalination, 267(2-3), 193-200. 